\title{
Process and Dynamics of Social Innovation: Case Studies of Local Initiatives in Northern Thailand
}

\author{
Alongkorn KHUTRAKUN
}

\begin{abstract}
This article highlights how social innovation emerged, integrated, and expanded in local community settings. The paper presents findings summarized from a qualitative study of three local initiatives as case studies of social innovation. A "Social Innovation Framework" is subsequently proposed to represent the relationship between the social innovation process and social innovation dynamics. The framework shows that each step in the process leads to changes in the characteristics of the social innovation accordingly in that it makes social innovation more practical and increases the level of the community member's participation.
\end{abstract}

KEYWORDS: Social Innovation, Local Initiative, Collaboration

JEL CLASSIFICATION: Z00

\section{INTRODUCTION}

Almost all social problems are complicated, context-dependent, and cross-boundary. An individual or an organization alone cannot solve these problems effectively. Waste disposal, for example, is one of the most general problems found in many areas. Some authorities choose to increase the number of their garbage trucks to cope with the increasing waste in their area. Unfortunately, such a solution does not solve the problem because it is just a reaction to the symptom of the problem. The underlying cause of such a problem actually lies on the belief that waste disposal is a responsibility of the government, not the people. People produce as much waste as they like and leave that waste to the authority to remove. Some communities, however, do not rely on the government. They "manage" the waste they produced by themselves before leaving some unrecyclable or hazardous waste to the authority. This simple phenomenon depicts a change in attitude towards the waste of some groups of people, and when most of the people change, social innovation emerges.

Social innovation is all around us in the real world. Apart from that waste management example, we have a variety of types of social innovation ranging from the macro-level social innovations such as the government's creative policies to the micro-leveled ones such as debt management in the community.

In academic term, however, there is very little literature on this topic. Existing knowledge is mostly focused on business innovation rather than social innovation. Since social innovation differs from business innovation, knowledge about business innovation cannot apply to social innovation directly. Therefore, to clearly understand social innovation, a body of knowledge in the social innovation's domain must be generated. In addition, popular research theme on innovation is an adoption of innovation (Rogers, 2003). While an adoption, one of the phases in the innovation process, is very important especially to an organization, it is equally important to gain more understanding on the other phases of the innovation process including a generation and an expansion phase. In the field of social

Alongkorn Khutrakun, D.P.A., is a lecturer at the Faculty of Political Science and Public Administration, Chiang Mai University, Thailand. His research interests include social innovation, knowledge management, information systems in public sector, and human resource development. 
innovation, it is imperative to understand all of these phases systematically because we do not want people to just adopt social innovations, we want them to be creative and be able to create a context-specific social innovation suitable for their society.

This paper presents an inquiry into social innovation. It begins with defining and characterizing social innovation. Then, based on a qualitative research approach, local initiatives as case studies are analyzed in order to gain more understanding about social innovation dynamics and process.

\section{SOCIAL INNOVATION: DEFINITION AND CHARACTERISTICS}

\subsection{Definition}

Praves Wasi--Thailand's influential thinker--broadly defined social innovation as a development which based on a concept of living together in the society. (Wasi. P., 2003 quoted in Health Systems Research Institute, 2003: 3-4). While this definition is useful in terms of giving the universal purpose of social innovation, it is far too abstract for using either in research or in practice.

In 1970, James Taylor gave a more concrete definition by defining social innovation as "improved forms of action and new ways of doing things" (Wilmot, 2003: 22). This is similar to what Chuenruthai Kanchanachitra and Wassana Im-em summarized from the interviews with various scholars in Thailand. They defined social innovation as new things, including thoughts (or imagination), opportunities, and actions, that solve the problem or make a better society (Kanchanachitra, C. and Im-em, W. quoted in Health Systems Research Institute, 2003: 19). In addition, Geoff Mulgan et al. gave an institutional definition of social innovation as he suggests: social innovation is an innovative activity or service that is created for social purpose and, most of the time, is developed and diffused by socially motivated organizations (Mulgan et al., 2007: 8)

In this paper, social innovation is a new pattern of practice that differs from what people usually practice in a certain situation because of a change in their values or beliefs. This new practice, if adopted by most of people in the community, creates a relative advantage to individuals and community as a whole. Individuals involved in this process of change are motivated by collective benefits for the community. In terms of an operational definition, social innovation is a set of new and socially valuable activities, which are initiated and implemented by people who live in that particular area.

\subsection{Characteristics}

Synthesized from literatures, social innovation has three defining characteristics; social value, newness, and social motive. These three characteristics distinguish social innovation from the other innovation such as annual policies, recurring projects, and routine activities.

Social innovation must create value to the whole community. Members of a community can realize such a value equally in terms of opportunity. Essentially, social innovation creates value because it changes people's belief so that they behave in the better way. Moulaert et al. (2005) stated that social innovation creates value in three dimensions. First of all, social innovation has value because it fulfill people's previous unfulfilled needs or the needs that they still require but no longer available. Secondly, the value of social innovation is recognized when it improves the relationship among members of the community. Finally, social innovation increases not only people's social and political capabilities, but also the accessibility to natural resources.

Newness is another necessary characteristic of social innovation. It differentiates innovation from ordinary development programs. Social innovation needs to be perceived as "new" in the context of the related community; it does not have to be "new" for the others. It is not important whether the newness comes from an incremental or a radical change, i.e. a small adjustment in an ordinary 
behavior or an evolutionary project.

An initiative cannot be called social innovation if it is not based on social motive. People who engage in a social innovation process do not intend to take benefits for their own; instead, they try to create valuable social innovation for the whole community. It is possible for everyone to reap such a benefit. There is no financial gain or loss when it comes to social innovation.

\section{METHODOLOGY}

The research conducts nine studies in nine local communities using "local initiatives" founded in northern Thailand as case studies. These cases can be categorized into two groups: "main case" and "sub case". Three main cases, which are the focal points of this research, are used to study the social innovation process, dynamics, and its successful conditions. For each main case, two sub cases are conducted particularly for studying the expansion phase in social innovation process.

Case studies were selected based on two fundamental principles: distinctiveness and diversity. That is, local initiatives that were chosen must be unique in some way compared to others in a similar mold; and those initiatives must be varied in terms of their characteristics.

The overall criteria for selecting cases were (1) the qualified local initiatives must possess all of social innovation's defining characteristics and (2) they must be initiated and implemented by members of that local community. For main cases, additional criteria must be met including (1) local initiatives must have been already integrated into the community and (2) local initiatives must be different in their focus, age, and source. Moreover, for sub cases to be selected they must (1) have the same or similar purpose to the related main case, (2) occur after the related main case, and (3) have received information or knowledge about initiatives from the main case.

Table 1: Summary data of main case studies

\begin{tabular}{|c|c|c|c|}
\hline \\
\hline & Baan Sarm Kha & Baan Dong & Baan Rai Noi \\
\hline Population & $656(152)$ & 664 (153) & 387 (127) \\
\hline Ways to earn income & Farmer and Hireling & Farmer and Hireling & Farmer and Hireling \\
\hline Distance from city & 40 Kilometers & 60 Kilometers & 20 Kilometers \\
\hline Name of Initiatives & Debt management & Alcohol-Free Funeral & Waste Management \\
\hline Aims & $\begin{array}{l}\text { Decrease debt, } \\
\text { Increase income, and } \\
\text { restructure debt }\end{array}$ & $\begin{array}{l}\text { Ban alcohol beverage } \\
\text { from a funeral }\end{array}$ & $\begin{array}{l}\text { Decrease quantity of } \\
\text { waste in the } \\
\text { community }\end{array}$ \\
\hline Start year & 1998 & 2001 & 2006 \\
\hline Focus & Economics & Social and Cultural & Environmental \\
\hline Initiated by & Villagers & $\begin{array}{c}\text { Villagers and external } \\
\text { coordinator from } \\
\text { TRFRO }\end{array}$ & $\begin{array}{l}\text { Villagers and } \\
\text { municipality }\end{array}$ \\
\hline
\end{tabular}

* (number) $=$ households

Complying with these criteria, the chosen case studies included Debt Management at Baan Sarm Kha, Mae Tha sub-district, Lampang province, Alcohol-Free Funeral at Baan Dong, Huar Saer sub-district, Lampang province, and Waste Management at Baan Rai Noi, Muang Noi sub-district, Lamphun province. Table 1 displays summary data for each of the main cases and selected characteristics of their local initiatives. As shown in Table 1, these selected main cases are both similar and diverse, for example, the selected communities are all relatively small and they all earn their income in the same way. In terms of the diversity, the distance from city ranges from approximately 20 kilometers to 60 kilometers, and the age of initiatives ranges from 4 years to 12 years.

In-depth, semi-structured interviews were conducted with 30 villagers. Heads and active members of 
the teams responsible for pursuing the initiatives from each case were selected to be key informants. Furthermore, three external individuals who know the community inside-out were also interviewed in order to gain validity of information received from the key informants.

\section{ANALYSIS}

\subsection{Social innovation dynamics}

Learning from this study, social innovation dynamics is, in essence, a change the pattern of social innovation. This change relates to each phase of the social innovation process. From nothingness, the first change occurs when an interesting thought pop up in initiator's mind; let us call it a "good idea". A good idea is a creative thought which helps in developing the community or solving a current social problem.

This very first form of social innovation remains in its abstraction state until it has been put into practice by initiator himself or someone that recognizes its value and is able to use it. Once someone takes that idea to practice, social innovation changes its form to be an "immature social innovation". For example, when someone in the village of Baan Sarm Kha practices household accounting, then the debt management social innovation begins or when the first funeral in the Baan Dong village held by not offering guests any alcohol beverage, then the alcohol-free funeral social innovation begins or when the villagers of Baan Rai Noi first bring their recyclable waste for selling at Waste Separation Center, then the waste management social innovation begins.

It is "immature" because it lacks participation from most of the people in the community. In addition, there might be some problems with activities that need to be improved in terms of their effectiveness and efficiency so that they could be adopted more easily. Household accounting is an excellent example of this situation. When first introduced, the household accounting includes too many categories of expenditures to be recorded that do not suit the Baan Sam Kha's villagers' behavior. As a result, people who adopt this practice find it difficult to use the account. After this issue has been resolved, people start to notice the real benefit of this practice and they are more willing to "give it a try”.

The third change in terms of form of social innovation occurs when most of the villages adopt the social innovation. The "mature social innovation" is a full-functioned social innovation that is able to change people's behavior in accordance with its purposes. At this stage, social innovation becomes a "routine", that is, most of the people in the community have changed the way they behave. For instance, Baan Sarm Kha's villagers have changed from not carefully using loan money to purposefully making the loan money productive.

Social innovation could still change after its mature state. To begin with, social innovation may change its functions in order to get more effective and efficient in relation to its original purpose. This form of social innovation is called an extension of mature innovation. A good example is found in Baan Dong's case study. After successfully dismissing alcohol beverages from every funeral, Baan Dong's villagers were eager to make a funeral as cost-effective as possible. They initiated various activities; the most notable one was the do-it-yourself coffin that reduced the cost of the funeral significantly.

Alternatively, a "new good idea" could emerge from a mature social innovation as we can see in Baan Rai Noi's Youth Development program. Youth members of the Waste Separation Center were encouraged to be involved in the management tasks of the Center. From this activity, the team had learned that teenagers in the community had a lot of potential. Hence, giving them opportunities to take actions in societal matters should be a key driver to their development.

Finally, social innovation may diffuse from the original community to other communities. More often than not, original social innovation is modified when it is adopted by the other community. 
Unfortunately, the research found that only 50 percent of sub-case studies successfully adopted social innovation from the originators.

\subsection{Social innovation process}

Social innovation process is a pattern of procedures and actions that relate to the creation phase, integration phase, and expansion phase of social innovation. Social innovation is evolvable. It is in the abstract form when it first emerges. If the key conditions are provided, social innovation will change gradually to be more concrete form. After achieving the highest concrete form, social innovation tends to transform to be in an abstract form again. Most social innovations are created purposefully by people in the society. Hence, the change in social innovation depends largely on people's actions. Put another way, steps in changing social innovation from the most abstract to the most concrete is called the social innovation process.

Social innovation process has two levels; individual level and team level. On the one hand, in order to create, integrate, and expand social innovation, a large number of individuals must be involved in the process. All of them, essentially, must change their own behaviors in a certain situation. On the other hand, in order to pursue the tasks of creating, integrating, and expanding social innovation effectively and efficiently, a team, which is directly responsible for managing these tasks, is imperative.

Individual level:

Individuals play their own roles in the social innovation process. Even though the process of social innovation needs a number of individuals to participate, at the beginning it requires as little as one individual to be involved since it is about "perception" and "imagination". Perceiving of what is a problem or an undesired situation currently found in the community is the first step. Based on that perception, then, an individual may be able to initiate a solution for that particular problem. The idea could be left on individuals' head forever, or it may be put into "practice".

A good idea can be useful only if it is practiced. Naturally, an initiator is the first mover since he/she is an originator of such a good idea. If the practice is found useful, then he/she would tell his/her relatives, friends, and neighbors. This phenomenon is called "expanding common consciousness".

When the practice has been adopted for some time and its benefits are fully perceived, then people will "practice it commonly and regularly". At this stage, individuals actually change how they behave in the past completely. They do not have to decide whether they will do it or not, they just do it automatically.

While an individual's continuous practice of new idea is the most important aspect of social innovation process, the efforts of the team is also directly related to the change in social innovation.

Team Level:

Social innovation process usually "carries on" by a community or a team. Notice that social innovation process is indeed a group of actions that (1) attempts to bring a good idea into practice, (2) helps integrate social innovation into the existing social system, and (3) expands social innovation to a broader context. This set of actions drives social innovation to evolve.

Inductively analyzed from the cases, the study found that several steps occurred in the first phase called "Creation Phase". First of all, people in the community recognized what the problem was. Then, they opened themselves to new information and knowledge or even generated new knowledge in order to cope with the problem they were confronting. Observations from cases confirmed this statement. As in all case studies there were interactions between villagers and people outside the community that finally generated good ideas from those interactions. At this phase, a team was formed informally and loosely and centered on an initiator. 
The emerged good idea may be shared to other people in the community. Advantages and disadvantages of the idea will be analyzed through the process of dialogue. An initiator and his team usually took an active role in selling their ideas to friends and neighbors. The strategy they used was to start talking with community leaders first. This strategy proved effective especially in the local village the informal relationship is so influential. Getting the "green light" was a guarantee of support from those people, which is crucial when you are about to create something new in the community. Unfortunately, not all good ideas are accepted and if the team paid no attention to this fact or pretended to ignore it, then, those good ideas may be practiced but they would never be matured social innovation.

The typical way to decide whether the good idea should be pursued in the community level is to set up a "people forum". A "people forum" is a key mechanism commonly used in a local community to reach a consensus agreement on particular issues.

If the majority of the villagers in the "people forum" accept the good idea, then the team will be set up formally, usually consists of at least 10 active members. Extracted from case studies, the team normally consists of two groups of people; (1) respectful figures in the community such as the head of the village, teachers, monks, and retired government officers; and (2) initiator of the good idea and some active villagers. For the start, the team usually identifies the aims and scope of the social innovation to be pursued before they create activities in accordance with those aims.

The next phase in social innovation process is called "Integration Phase". At this stage, the activities created by the team are introduced in the community for some time and some villagers are practicing those new activities. In the regular meeting of the team, there will be a discussion of how well each activity goes and what could be improved for achieving better results. After that step, the team tends to formalize the widely accepted activities mostly by assigning written regulations for them. At the same time, the team attempts to publicize the success of current activities to the whole community. With active and continuous support from the team, in collaboration with the participation of individuals, the social innovation could be integrated into the community.

The final phase in social innovation process is an "Expansion Phase". One of the most striking features of social innovation is its ability to expand. After social innovation has been practiced seamlessly in the community, the team will evaluate the existing social innovation and initiate new activities using the experience from the previous process. The new activities may shift the focus from the current problem to other important issues in the community. Most likely, the team shares their knowledge and experience with other communities. This usually leads to the occurrence of social innovation in various communities.

\section{CONCLUSION}

Despite it being important, knowledge about social innovation is in the early stage. This study explores some of the key components of social innovation. I found that although process of social innovation is different among case studies, some common steps can be extracted. I also found that social innovation changes overtime. At least four forms of social innovation can be identified along the process of social innovation. Finally conditions related to the success of integration of social innovation were synthesized from the analysis, i.e. a combination of team's absorptive capacity and internal collaboration within the community. All of this knowledge was synthesized to be the social innovation framework. We hope the framework could contribute to a better understanding of social innovation, and could be a solid base either for practicing or for researching this subject in the future.

\section{REFERENCES}

Kanchanachitra, C. and Im-em, W. (2003). Nawat dat gam săngkom : Gaan hai kwam maai lae laksana gitja gam nai bra tayt tai (Social Innovation: Definition and Activities in Thailand). In Health 
Systems Research Institute 2003. Nawat dat gam sangkom: taang luak pua bra tayt tai rot (Social Innovation: Alternative for Survival of Thailand). Bangkok: Dee Publishing.

Moulaert, F., Martinelli, F., Swyngedouw, E., and Gonzalez, S. (2005). Towards Alternative Model (s) of Local Innovation. Urban Studies, 42(11): 1969-1990.

Mulgan G., Tucker S., Ali R., and Sanders, B. (2007). Social Innovation: What Is It, Why It Matters, and How It Can Be Accelerated. Retrieved August 10, 2007. Retrieved from

http://www.youngfoundation.org/publications/reports/social-innovation-what-it-why-it-matters-h ow-it-can-be-accelerated-march-2007

Rogers, E. M. (2003). Diffusion of Innovations. $3^{\text {rd }}$ ed, New York: The Free Press.

Wasi, P. (2003). Nawat dat gam sangkom: taang luak pua bra tayt tai rot (Social Innovation: Alternative for Survival of Thailand). In Health Systems Research Institute 2003. Nawat dat gam sangkom: taang luak pua bra tayt tai rot (Social Innovation: Alternative for Survival of Thailand). Bangkok: Dee Publishing.

Wilmot, T. M. (2003). The Dynamics of Visioning and Social Innovation: A Grounded Theory Study of the Impact of Appreciative Inquiry in Sustaining Long-Term Organizational Change. Doctoral Dissertation, Case Western Reserve University. 